\title{
EL PUEBLO DE “FILIBUSTEROS” Y LA "RAZA DE MALVADOS": DISCURSOS NACIONALISTAS CHILENOS Y PERUANOS DURANTE LA GUERRA DEL PACÍFICO (1879-1884)
}

\author{
THE “FILIBUSTER” PEOPLE AND THE “WICKED RACE”: \\ CHILEAN AND PERUVIAN NATIONALIST DISCOURSES \\ DURING THE WAR OF THE PACIFIC (1879-1884)
}

\author{
Juan Carlos Arellano González*
}

\begin{abstract}
La Guerra del Pacífico es un momento trascendente para observar el despliegue de los imaginarios nacionales de chilenos y peruanos. Una instancia en la que se cristalizaron imágenes, percepciones e ideas que hasta hoy condicionan las relaciones entre ambas naciones. Este artículo plantea analizar los discursos guerreros durante el conflicto con el objetivo de desentrañar las representaciones del "enemigo", del "pueblo" y de la "nación". A partir del análisis de estas nociones será posible iluminar las ideas y sentimientos que chilenos y peruanos se forjaron durante el conflicto. La hipótesis plantea la existencia de un discurso nacionalista que apeló a la exaltación de componentes culturales y raciales del enemigo otorgándole un sentido que desborda las razones circunstanciales de la guerra. Para esta retórica bélica, que asumen la guerra como un choque "cultural" y "racial", los imaginarios de los pueblos y los sujetos subalternos, reconocidos como "rotos", "araucanos" y "cholos", se transformaron en las palabras sustantivas para la concreción del discurso guerrero. La fuente predominante para esta investigación es la prensa escrita en la que es posible rescatar artículos, discursos, canciones y poemas creados en torno al conflicto armado.
\end{abstract}

Palabras claves: Guerra del Pacífico, discursos guerreros, nacionalismo, Chile, Perú.

The War of the Pacific is a key moment for observing the deployment of Chilean and Peruvian national imaginaries. It is a context in which images, perceptions and ideas crystallised which still condition relations between the two nations today. In this article we propose to analyse war-like discourses during the conflict in order to unravel representations of "the enemy", "people" and "nation". Analysis of these concepts will illuminate the conflicting perceptions and ideas which Chileans and Peruvians forged for themselves during the war. Our hypothesis is that a nationalist discourse existed which appealed to people to exaggerate cultural and racial components in the enemy, giving them a meaning which went beyond the circumstantial causes of the war. In this war-like rhetoric, in which the war is presented as a "cultural" and "racial" shock, the imaginaries of the peoples and their lower orders-recognised as "rotos", "araucanos" and "cholos", become heavily meaningful words in the creation of war-like discourse. The sources used in this investigation are the written press on both sides, which contained articles, speeches, songs and poems created in the context of the armed conflict.

Key words: War of the Pacific, war-like discourse, nationalism, Chile, Peru.

\section{Introducción}

La guerra fue un momento de alteridad significativo entre Chile y Perú. Ambas naciones se vieron arrastradas en una guerra de palabras, que claramente condicionó las relaciones políticas y las percepciones de ambos pueblos, palabras que dan sentido al conflicto armado sobre la base de una identidad que significó una instancia de definición de un otro y a su vez un ejercicio introspectivo. Declarada la guerra y establecidas las distinciones discursivas que buscaban darle el sentido al conflicto ante la opinión pública, fue necesario definir además las características de los pueblos en pugna. Esto obligó a que, con el transcurrir de los acontecimientos, se fueran incorporando nuevas imágenes y conceptos que se transformaron en un articulado ideológico bastante coherente y de carácter nacionalista en ambas naciones.

El nacionalismo fue propuesto primero en Chile como discurso legitimador de la guerra. Sin embargo, gradualmente en el Perú fue incorporado al lenguaje político republicano americanista, un repertorio de palabras que pueden ser circunscritas

\footnotetext{
* Universidad Católica de Temuco. Facultad de Ciencias Sociales, Departamento de Sociología y Ciencia Política. Correo electrónico: jarellano@uct.cl.
} 
más bien al nacionalismo. Esto no significó que durante la guerra el republicanismo americanista peruano fuera erradicado de las arengas, sino que ante las adversidades enfrentadas en el transcurso de la guerra oradores y publicistas peruanos se vieron obligados a incluir en sus arengas palabras que buscaban exacerbar características comunes de índole cultural y racial.

Civilización y barbarie se transformaron en los referentes para explicar la distinción entre uno y otro pueblo, en una verdadera vara para medir el estado de la evolución de las sociedades. A partir de esta concepción, la trayectoria política y de las instituciones, las características culturales y étnicas, los progresos materiales de las naciones fueron utilizados por publicistas y arengadores para establecer las distinciones entre los pueblos y así legitimar el conflicto. Parafraseando a Bradford Burns (1990), la preferencia de las elites por la idea progreso, cargada por corrientes como el positivismo y darwinismo social (Sánchez Arteaga, 2007), contribuyeron a otorgarle un sentido trascendental al conflicto dentro del concierto mundial.

Sumido bajo la concepción de la filosofía del progreso, el lenguaje político nacionalista comienza gradualmente a poner los énfasis en aspectos de tipo cultural y racial. Estos nuevos conceptos revitalizan al nacionalismo y lo vuelven asequible a un público mucho más masivo. En palabras del teórico político Maurizio Viroli (1997), estaríamos frente a un proceso de nacionalización del patriotismo. Viroli plantea la distinción entre un lenguaje político patriótico y uno nacionalista. El primero se refiere a un lenguaje que se remonta hasta el mundo antiguo, que invoca fundamentalmente el amor caritativo de sus ciudadanos a la república y a sus leyes. Al contrario, el nacionalismo demanda valores como la homogeneidad cultural o étnica del pueblo, exigiendo la "lealtad incondicional" de su pueblo. El lenguaje nacionalista exaltaría una pasión que considera natural, al nacer de una determinada condición cultural o étnica. Con esto se impone un argumento moral, que obliga a los integrantes de esa comunidad a comprometerse con el pueblo del que se es parte, y que es imaginado como un alma espiritual.

El lenguaje político nacionalista chileno desatado en la Guerra del Pacífico como instrumento para promover la cohesión y la movilización nacional fue alineado a partir de la confluencia entre las nociones de orden y progreso. Estos conceptos claramente se alejan de un discurso chovinista al que Claudio Véliz (1980: 163-64) denominó como un nacionalismo extrovertido (Jocelyn-Holt, 1998). La paradoja está en que conceptos como orden y progreso, en el lenguaje bélico, alcanzan un doble sentido; por tanto estos conceptos se sumen en una concepción mucho más amplia que dice relación con el mundo de Occidente, construido sobre la polaridad entre la "civilización y barbarie". Esta concepción se convierte como un indicador para definir las características de los pueblos (Starobinski, 1999). De esta forma el lenguaje nacionalista se insertó dentro de un universo más amplio, considerado como legítimo para justificar las acciones de las naciones. La grandeza y la competitividad de las naciones fueron definidas a base de estos ejes que sirvieron para legitimar la supervivencia y la desaparición de determinados pueblos. Este lenguaje no tiene nada de novedoso si lo insertamos como parte de la retórica imperialista colonial europea, propia del siglo diecinueve, en donde las potencias hegemónicas definen su gloria nacional en virtud de su preponderancia civilizadora (Howard \& Roger Louis, 2002: 92).

Efectivamente, la mirada extrovertida del nacionalismo chileno necesitó de una cuantiosa dosis de particularismo, para darle sentido al conflicto y motivar así a sus ciudadanos a realizar sacrificios extraordinarios. La característica exógena del discurso se complementó como mirada endógena, que realiza una reflexión introspectiva, sustentada en la historia nacional que fue narrada con un marcado sentido de alteridad. La historia nacional se transforma en un insumo crucial para el diseño de los discursos, la que al mismo tiempo es utilizada como arma ideológica capaz de legitimar el conflicto, otorgándole un sentido que está por sobre las causas circunstanciales que lo provocan. Este componente endógeno es destacado por Gabriel Cid (2009) al reconstruir la representación del roto como "ícono nacional", subrayando que en el contexto de la guerra se convierte en una figura clave en los discursos bélicos que exaltaron la etnicidad como elemento diferenciador.

La historia nacional comenzó a ser interpretada bajo la polaridad "civilización y barbarie", utilizándose como eje distintivo para definir a los pueblos. Debido a que no existía una diferencia tan rotunda, en términos culturales o étnicos entre las naciones en pugna, lo que los diferenciaba era su breve historia nacional, que a partir del proceso 
emancipador habían tomado caminos distintos. No es de extrañar entonces que por medio de los ojos de la concepción civilizadora se hayan rescatado ideas del viejo lenguaje republicano, como la exaltación del orden político, el que fue complementado con la noción del progreso material y social. Para desentrañar este lenguaje político nos sumergiremos en los discursos y los artículos publicados en los periódicos chilenos y peruanos durante la guerra, reconstruyendo el tejido discursivo de la época ${ }^{1}$.

\section{Chile: la cruzada regeneradora}

Desde la ocupación de Antofagasta la retórica bélica fue inscrita en estos códigos nacionalistas que pusieron su énfasis en el orden y el progreso. La Revista del Sur de Concepción justificaba la ocupación chilena arguyendo que "el desierto de Atacama es y solo puede ser chileno", señalando que Bolivia presentaba una "constante y perpetua anarquía y desorden, realmente sin un gobierno organizado; sin capitales, sin industria, sin espíritu de empresa y hasta sin hábitos de trabajo". Para este publicista, Chile era el único capaz de aprovechar las riquezas del norte, ya que estas "solo brotan al calor de grandes capitales y de una industria bien adelantada y regadas con el fecundante sudor del incomparable trabajador chileno" (La Revista del Sur, Concepción, 13 de marzo de 1879, 2). En función del progreso, entonces, se hace legítima la ocupación de un territorio, y en donde los tratados y las causas coyunturales pasan a segundo plano cuando lo que está en juego es la inclusión de toda una región al estatus que exige la civilización.

Declarada la guerra, la opinión pública chilena participó comprometidamente en la propagación y creación de un lenguaje político de índole nacionalista. Los conceptos e imágenes argüidos desde los periódicos y mítines revelan la existencia de un lenguaje en común que al unísono, desde diferentes rincones de la nación, fue exacerbado como una herramienta para despertar un espíritu nacionalista capaz de generar la cohesión necesaria para enfrentar el conflicto que se les avecinaba. La opinión pública de ninguna forma puede ser considerada en este sentido como un actor refractario de las esferas del Estado. Sino por el contrario, desde la esfera pública se ejerce la presión para influenciar al gobierno en la dirección de la guerra y se aportan los argumentos y conceptos necesarios para legitimar el conflicto ${ }^{2}$. Su influencia se hará sentir en momentos clave de la guerra, alabando el asalto a Pisagua o presionando para invadir Lima, la "ciudad de los virreyes". Consciente de su poder, esta nueva esfera pública se transforma en un actor crucial en la creación del contenido y en el despliegue de un lenguaje político capaz de encender el espíritu belicista de las masas.

Palabras como regeneración, orden y progreso serán el piso para que luego se construya un discurso nacionalista que glorificará la idea de una raza, exaltando los personajes y mitos necesarios para la creación de la idea de nación o de pueblo. En este lenguaje, la guerra a Bolivia y Perú se explica en función de elementos universalistas, como la idea de progreso que sería representada por uno de sus hijos predilectos, el que históricamente y producto de sus cualidades tendrá la tarea de regenerar a estos pueblos vecinos que aún se encuentran sumidos por la barbarie. En la construcción subjetiva de la realidad, Chile se ubica entonces como el paladín de los valores universales (como progreso y orden), atendiendo a argumentos que apelan a elementos diferenciadores de carácter cultural como la raza o costumbres de un pueblo. Estos conceptos serán utilizados como argumentos legitimadores de las diferentes acciones bélicas emprendidas por el gobierno y los militares chilenos.

La guerra para los publicistas y oradores chilenos fue definida como una regeneración o como un castigo. La historiadora peruana Carmen McEvoy plantea que la polaridad discursiva en Chile era construida de forma básica como la lucha entre el "bien y mal", "civilización y barbarie", asignándole a esta última las imágenes de la corrupción, el vicio, la lujuria y el ocio $(2007,2010,2011)$. Sobre la base de esta legitimidad, la guerra simbólicamente significaba el castigo que a una hija predilecta del progreso le confería a un pueblo bárbaro ajeno a de toda virtud como una instancia regeneradora.

No es de extrañar entonces que el arribo a Chile del escritor y periodista Rafael Vial desde Lima, provocada por la tensión entre ambas naciones, se haya transformado en un hecho célebre en la ciudad de Santiago (Figueroa, 1901: 441). En sus primeras líneas escritas en abril dirige su mirada a la clase política peruana al señalar: "El Perú es una factoría gobernada en beneficio propio por una docena de ávidos especuladores [agregando que los] partidos, en vez de representar ideas representan especulaciones de mala índole". El diagnóstico aún no es categórico con el pueblo peruano, ya que lo acota 
más bien a una clase política corrupta: "el país es bueno, pero se encuentra avasallado por malvados incorregibles". En este caso, la guerra se presenta ante la tribuna pública como una necesidad, una "redención", que tiene por objeto restablecer en el Perú la moralidad administrativa, castigando con severidad a los "criminales" (El Independiente, Santiago, 19 de abril de 1879, 2).

Lo declarado por Vial respecto de a la clase política peruana es parte de un discurso transversal en la opinión pública chilena. En el pueblo de Yumbel, un periódico días antes esgrimía los mismos argumentos que pretendían otorgarle al conflicto categorías normativas que estuvieran en sintonía con los cánones de la civilización y el progreso. Para el redactor de El Republicano, Manuel Bernales, el Perú sería un lastre para los pueblos americanos que se encuentran insertos en el redil del progreso. En manos de "hombres laboriosos y honrados", arguye Bernales, las grandes riquezas del Perú podrían satisfacer "las necesidades de la América toda"; el problema está, continúa este publicista, en su clase dirigente -"los hijos de Atahualpa"-, que son un "foco de corrupción y miseria". La guerra es entonces un choque cultural entre un pueblo representante de las virtudes del progreso, enfrentado a una "nación que existe solamente para dar a las otras del mundo entero el escándalo de continuas intrigas y de asesinatos, en el palacio de gobierno" (El Republicano, Yumbel, 9 de abril de 1879, 2).

La mirada hacia el pasado se constituye como parte vital del discurso para explicar el presente y avizorar el futuro. En San Felipe, Juan Ruiz, en las páginas de El Chacabuco, saluda a la "Patria amada" en su aniversario. En una construcción idílica de Chile la guerra es impulsada "por rabiosa envidia a nuestra prosperidad y bien estar” y dice Ruiz " $\mathrm{OOh}$ raza de malvados!" descentrando el problema de la clase política, extrapolando el castigo a todo el pueblo peruano. Las palabras de Ruiz son selladas con duros términos que establecen el sentido regenerativo de la guerra:

Cuando los pueblos se prostituyen como Perú y Bolivia, la justicia Divina entrega sus cabezas a la espada de otros pueblos para lavar las iniquidades; pues bien, a Chile le ha tocado en suerte castigar las maldades de aquellos desgraciados, y menester es que cumpla su misión regeneradora infringiéndoles un saludable escarmiento $(E l$
Chacabuco, San Felipe, 18 de septiembre de 1879, 1).

La regeneración que se esgrime al interior de la esfera pública chilena se sostiene por la invocación a un pasado que es leído como un progreso lineal y ascendente, convirtiéndose en un argumento clave para legitimar el restablecimiento moral y físico de un pueblo alejado de los valores, los que son rectores de las naciones americanas. El Pueblo Chileno se alinea con el discurso regenerador incluyendo en sus páginas conceptos vinculados a la medicina y la salud, al diagnosticar en el Perú una sociedad enferma y en la que Chile tiene la tarea de extirpar la podredumbre "sin odio, pero con la resignación del cirujano que amputa la gangrena, adelante compatriotas en la misión que llevamos!" (Antofagasta, 18 de septiembre de 1879, 2).

El lenguaje regenerador fue polarizado y alimentado principalmente por los triunfos chilenos alcanzados en el norte. La captura y derrota del Huáscar en el combate naval de Angamos, el 8 de octubre, y el exitoso desembarco en Pisagua, se convirtieron en pruebas en este discurso de la superioridad chilena, gracias a su orden y su sintonía en la senda del progreso. El Mercurio de Valparaíso, por medio de sus columnas, participó de esta idea regeneradora utilizando un lenguaje muy virulento:

El Perú, nación corrompida hasta la médula de los huesos, mas degradada aun que esos pueblos asiáticos que se rebullen en perdurable ignorancia, no podía por más tiempo estar sirviendo de foco de revuelta y desmoralización a países que como los que tienen su asiento a orillas del Pacífico han menester para vivir de consagrarse exclusivamente a las tareas de la paz, que es trabajo y progreso (Valparaíso, 24 de noviembre de 1879, 2).

No es insólito que en el discurso de El Mercurio de Valparaíso se ocupen las mismas imágenes y conceptos argüidos por El Pueblo Chileno, en septiembre, al señalar que la vecindad de Chile con el Perú ha sido "hasta aquí la vecindad de un leproso cuya infección amenaza hora a hora su salud robusta" y que ante tan peligrosa situación se requiere tomar acciones: “¿Cómo, pues, podía continuar el Perú infestando a la América con su disolución, maquinando constantemente la ruina de 
Chile y ultrajando con sus escándalos la moral del mundo?" La respuesta en esta lógica es bien simple: la guerra se convierte en un proceso purificador que tiene como fin el extirpar los agentes que descomponen este cuerpo americano. En este discurso, Chile solo ha "sido más que el instrumento" para ejecutar el castigo por desviarse de la senda modernizadora (Valparaíso, 24 de noviembre de 1879, 2).

La opinión pública chilena se embriaga con el triunfo obtenido por el ejército en Pisagua. " $i \mathrm{~A}$ Lima! ¡A Lima!”, exclamaba La Revista del Sur de Concepción, que se alinea con la retórica bélica regeneradora, al afirmar que la derrota sufrida por las fuerzas enemigas es el precio a pagar para que quede bien "establecida nuestra superioridad moral y material sobre ese pueblo". La invasión a Lima significa mucho más que una estrategia para terminar el conflicto y fijar los términos de la paz, es también para:

...probarle al mundo que el camino de esa infame ciudad, de esa Sodoma o Gomorra americana se halla por fortuna siempre abierta [y que este camino] lo recorrerá cuantas lo exijan su paz, su tranquilidad y sus legítimos intereses a los de la civilización y de la América (La Revista del Sur, Concepción, 27 de noviembre de 1879, 2).

La guerra queda de esta forma como una redención que supera los ribetes nacionales para transformarse en una victoria de la civilización y el progreso de América. La Araucanía de Mulchén, celebra la victoria de Pisagua retratando en forma espléndida este espíritu civilizatorio, que hegemonizó a la opinión pública chilena y señaló que: "el ejército chileno que hoy ocupa el territorio de los incas... llevará también la regeneración a esa nación envilecida, que fraguaba pactos secretos para detener y aniquilas nuestros progresos" (30 de noviembre de 1879, 2). El progreso se hace presente en el ejército chileno con el fin de redimir a todo un pueblo. La Verdad de Valdivia, ante los triunfos chilenos en Tarapacá, establece que la corrupción, concepto fundamental dentro de la concepción regeneradora chilena, es el factor que explica el caos político que se ha generado en el Perú luego de las derrotas bélicas:

Ese pueblo de Lima, tan orgulloso, tan fanático y tan corrompido; ese pueblo, que presto idolatra como se come y arroja a la hoguera a sus prohombres; ese pueblo, en donde la corruptela administrativa, militar y eclesiástica han sido legendarias; ese pueblos, decimos, que tales cosas hace y que hoy se encuentra desesperado y próximo a hundirse para siempre en un abismo" (La Verdad, Valdivia, 4 de enero 1880, 2).

El fracaso de Perú y Bolivia en la campaña de Tarapacá significó entonces un punto de inflexión en el discurso regenerador chileno. Inmersos en esta idea de progreso -concepción propia de las naciones civilizadas-, que en esta cruzada bélica se enfrentaba ante la barbarie, el triunfo de Tarapacá simboliza el primer paso para la regeneración. Así lo entendió el redactor Amador Astullido de El Correo de Quillota, al preguntarse: "¿Quién sabe si la desgracia que hoy pesa sobre el Perú no será el primer paso dado en el camino de su futura regeneración y prosperidad?". El argumento de Astudillo lo conduce incluso a plantearse la idea de convertir a Chile en una especie de tutor de Perú, que lo inserte dentro del camino de las naciones civilizadas: “¿Qué valor tiene la autonomía de un pueblo que ha sido torpe dilapidación, atraso, vicio, ignorancia y miseria?" (El Correo de Quillota, Quillota, 8 de enero de 1880, 2).

En este aspecto, el discurso regenerador promotor de destrucción y erradicación adquiere en momentos un sentido fraternal, pero anclado en una autoridad moral. "Chile salvará al Perú", decía José Mujica en las columnas de El Pueblo Chileno. Su argumento lo fundamenta sobre la base de la autoridad moral que Chile tendría en América, arguyendo que "Nos preocupamos del Perú como en el seno del hogar nos preocupa la suerte del hermano descarriado". Sin embargo, solo el castigo es la forma de redimir a este pueblo hermano, que solo con "cauterio de fuego extirpará la gangrena que viene corroyendo sus entrañas y con estos Chile hará una obra de humanidad" (El Pueblo Chileno, Antofagasta, 10 de enero de 1880, 2).

No obstante, el discurso se radicaliza ante la obstinación de un pueblo que se niega a ser vencido. El carácter fraterno del discurso es desplazado para que se imponga el discurso ponzoñoso y destructor. El tenor de la regeneración durante esta campaña, entre enero y junio de 1880, es retratado en las palabras de Clemente Suárez, redactor del periódico El Censor de la ciudad de San Felipe. En este periódico se observa este espíritu destructor marcado 
por el odio, esgrimiendo que para "los maricones del Perú y los raposos de Bolivia el desenlace no puede ser otro que el aniquilamiento", única solución diagnosticada para el Perú (El Censor, San Felipe, 7 de marzo de 1880, 2).

Este mismo argumento es refrendado por Juan de Dios Riva en Mulchén, curiosamente el mismo día en que publicó Suárez, utilizando un lenguaje menos prosaico se refiere a Perú como:

“...el omnímodo Sila principia a bambolear, como los edificios construidos sobre arena [y cuando finalmente caigan será] Chile con su justiciera espada cortará la última cabeza de esa hidra de Lerna que por tanto tiempo se ha enseñoreado en el Perú y Bolivia, y renacerá la paz para que se cumpla esa ley eterna que debe regir los pueblos: la ley del progreso, de la civilización" (La Araucanía, Mulchén, 7 de marzo de 1880, 2).

Para Riva, el papel de Chile en esta guerra es justiciero, una tarea que conscientemente acarrea el odio de muchos, pero que es necesaria dada que esta nación insertará al Perú, a su juicio, en el trayecto de las naciones civilizadas. De esta forma el discurso bélico regenerador le otorga a la guerra un rol que escapa al simple conflicto armado, transformándola en una verdadera epopeya que transciende incluso la temporalidad misma del enfrentamiento.

Esta idea regeneradora se sostenía respecto de la creencia de una superioridad de Chile sobre sus vecinos, avalada por su historia republicana y por consagrar los triunfos en las batallas recientes. De esta forma la historia y los acontecimientos son elementos fundamentales para la constitución de este discurso bélico regenerador. El lenguaje político de los publicistas chilenos fue coherente, por ejemplo, El Correo de Osorno, analizando el "porvenir de la Alianza", ocupa los mismos argumentos que legitiman la regeneración del Perú. En esta construcción retórica, la regeneración es una fórmula para enderezar a un pueblo que ha perdido el rumbo y que solo una nación portadora de las virtudes civilizadoras logrará corregir: la "regeneración de esa raza compuesta de esquilmadores y esquilmados la efectuaría Chile, el laborioso, el honrado, el progresista". Con esta regeneración desaparecerían "los funestos reyezuelos que han hecho desde su independencia, de Perú y Bolivia, dos cortesanas en vez de repúblicas, dos cortesanas a quienes han robado su dinero y su honra". La mirada retrospectiva es crucial en este discurso regenerador, para que adquiera características comparativas bajo el lente claro del progreso. El papel de Chile en esta guerra es de "El Ángel de la Justicia" (El Correo, Osorno, 19 de junio de 1880, 1).

En este discurso, un elemento clave para establecer la diferenciación era la historia, la mirada retrospectiva invita a marcar las diferencias entre Chile y los pueblos con los que combatía. Pero este mirar al pasado está influenciado por la noción de progreso, el que apunta principalmente al orden político. La trayectoria política de las naciones son la prueba para calificar si estas se habían empapado del espíritu del progreso, considerado como propio de las naciones civilizadas, por lo que quienes no se incorporaban a esta senda merecían el castigo, ya que la característica fundamental de este discurso es su carácter hegemónico y universalista. La hegemonía de este pensamiento dentro de la opinión pública chilena motivó al periódico El Caupolicán de Rengo a escribir en un tono sarcástico y sentencioso: "El Perú, ante las naciones civilizadas, representa la figura de una nación, la alegoría de una nación, cuyos pasos vacilantes y extraviado cerebro son el triste augurio de su próximo fin" (El Caupolicán, Rengo, 4 de julio de 1880).

Con esto, los arquitectos del discurso definían el sentido de la guerra estableciendo cuáles debían ser las condiciones de su término. Los conflictos limítrofes habían sido olvidados, subsumidos por un lenguaje y un imaginario épico que le otorgaba un carácter sublime. Paradójicamente, el nacionalismo apeló a principios que en aquella época eran considerados como universales e incuestionables, como la idea de progreso, los que fueron nacionalizados por la apelación de la historia nacional y corroborados con el éxito en las diferentes campaña militares. Chile, en este discurso nacionalista, se declara como el mejor representante del espíritu del progreso y, por ende, como un pueblo que cumple con todos los requerimientos de una nación civilizada. Las consecuencias de este discurso eran obvias: al considerarse una nación con tales cualidades morales y materiales, su papel dentro del continente no podía ser otro que el de cumplir con una tarea rectora o regenerativa.

Enterada la opinión pública chilena del desenlace de la guerra, con los triunfos de Chorrillos y Miraflores, a fines de enero de 1881, estuvo obligada 
a realizar un cierre al discurso regenerador. El afamado publicista de Quillota, Amador Astudillo, no tardó en hacer sus reflexiones, siendo consecuente con esta tendencia, sosteniendo que: "El castigo que hoy sufre el Perú guarda proporción con la enormidad de sus faltas" (El Correo de Quillota, Quillota, 27 de enero de 1881, 2). El triunfo en Lima sellaba el discurso regenerador que siempre dirigió su objetivo a la destrucción de esta ciudad, que era caracterizada como el foco de la corrupción y la decadencia. En este sentido, se construye un relato bíblico donde la imagen del cataclismo es la única medida para la purificación. De esta forma, ocupada esta ciudad por el ejército chileno, se cerraba un ciclo, estimándose que era la instancia para declarar el término del conflicto.

Con la entrega de la imponente Lima en manos de la fuerzas chilenas, la ciudad símbolo de la "degeneración" y ajena a los cánones de las sociedades civilizadas, se cumplía la meta fijada por este discurso bélico chileno, como lo señaló la declaración inserta de un periódico en Quillota: "Lima se había hecho una especie de diosa que debía ser la madre universal de la resistencia"; agregando que este hecho se convertía en un hito trascendental en la historia nacional y que dejaba a Chile en un posición inmejorable ante el concierto mundial (El Correo de Quillota, Quillota, 27 de enero de 1881, 2).

Lo anterior resulta muy gráfico en el discurso público de Emilio Calderón en la ciudad de Ancud, en Chiloé. Calderón glorificó este acontecimiento y sus gestores porque "nos han legado y nos legará todavía a la posteridad un nombre ilustre entre las naciones más cultas y civilizadas del orbe". Es un hecho sublime que va más allá de la victoria de las armas, sino que apeló a las naciones civilizadas y cultas. Agrega que Lima -"esa activa y soberbia Babilonia"- representa una imagen contradictoria con los cánones del progreso, narrativa en donde el rol purificador de Chile es inevitable y la guerra se hace ineludible, por lo que Calderón tajantemente esgrimió:

Y no podía suceder de otra manera; la planta del soldado chileno, lenta pero firme, debía hollar el suelo de esa Babilonia moderna, el escándalo de la América, para purificar la de sus crímenes, para hacerla una nación verdaderamente libre, honrada y amante a su decoro, y enseñarle en los infortunios a respetar siempre la bandera de paz de una nación que le tendió una mano protectora mientras ella maquinaba su ruina cobardemente allá en los antros tenebrosos de su congresos y de sus reuniones políticas: "Lima, señores, la orgullosa Lima ha caído, así como caerá cualquiera otra que ose insultar el glorioso nombre Chile" $(E l$ Chilote, Ancud, 5 de febrero de 1881, 2).

Con lo acontecido en Lima, el lenguaje político regenerador que se comenzó a tejer desde que se inició el conflicto con Perú y Bolivia se daba por satisfecho. La retórica bélica dentro de la opinión pública chilena cesó su virulencia y calmó su intensidad, pues era el momento de la celebración y de mirar el porvenir. Así lo declaró El Correo de Osorno, al afirmar que "la toma de Lima es el último canto de la sangrienta y colosal epopeya que ha escrito Chile en dos largos años de labor [...] El rudo desastre que el ejército peruano ha sufrido en los alrededores de Lima fue el último estertor de la agonía de un moribundo" y con un mirada hacia el horizonte, agrega: "volvamos nuestra vista a hechos sin sangre, sin cañones, sin pólvora; pensemos que la azada, en el martillo, en el yunque" (Osorno, 5 de febrero de 1881, 1).

Este sentimiento, momento cúlmine y desenlace definitivo de la guerra, que se apoderó de la opinión pública chilena, era sencillamente el resultado de una retórica que cerca de dos años refrendó la idea de que en la poderosa Lima se encontraba la verdadera causa que había gatillado la guerra.

\section{Perú: civilización y barbarie}

La concepción civilizadora fue también la matriz ideológica en donde se construyó el discurso nacionalista peruano. Retórica bélica que al igual que la chilena otorgó al conflicto ribetes que superaban las circunstancias coyunturales que lo detonaban, para enclavarse en una disputa que definía el destino de los pueblos civilizados. El americanismo republicano que sirvió como recurso retórico para legitimar la inclusión del Perú en el conflicto (McEvoy, 2007; Arellano, 2014), gradualmente derivó en un discurso nacionalista que incorporó elementos de índole civilizador para construir la imagen del enemigo, es decir, la de un otro.

La diferencia sustancial con la retórica chilena es que los publicistas y oradores peruanos no 
rompieron, por lo menos en los primeros y más intensos años de la guerra, con la tradición americanista. Esta limitación retórica les impidió forjar un discurso sólido con un componente nacionalista. El americanismo, como argumento para legitimar la inclusión del Perú a un conflicto, que hasta ese momento le era ajeno, de alguna forma trabó, discursivamente hablando, el surgimiento de una arenga guerrera que exaltara elementos nacionalistas como la etnia, la cultura o su memoria histórica, como lo fue en el caso chileno. Los márgenes por los que debía desplazarse el discurso eran mucho más reducidos que el de sus pares chilenos, ya que estos abiertamente quebraron con la tradición americanista de corte republicana. Los arquitectos del discurso en Perú debieron lidiar y complementar el discurso americanista republicano con el nacionalismo civilizador.

La historia nacional fue uno de los grandes insumos de la arenga guerrera chilena, no así de la peruana. Dos factores, a nuestro juicio, explican esta diferencia: primero, una historia nacional bastante convulsiva en términos políticos y sociales, marcada por las facciones y los caudillos, junto a una realidad social y étnica muy contrastante, tema que ha sido tratado por gran parte de la historiografía peruana. También existen factores coyunturales o circunstanciales, en términos retóricos, los que se refieren a argumentos ideológicos en donde se fueron construyendo los discursos, como lo fue el del imaginario americanista, que significó un doble esfuerzo para los arquitectos del discurso, que gradualmente debieron derivar en una arenga bélica de carácter más nacionalista.

Sin embargo, a diferencia del discurso nacionalista chileno, el ejercicio retórico fue mucho menos introspectivo. La arenga peruana apuntó a una construcción que se dirigía fundamentalmente hacia fuera y que rescató muy poco de su propia historia. El pasado nacional peruano, marcado por quiebres recientes dentro de la elite política peruana, dificultó el diseño de una retórica bélica que potenciara la cohesión social y política. Los argumentos persuasivos del conflicto fueron en este sentido mucho más coyunturales o mantenidos en un nivel de abstracción que no integró elementos de índole nacional.

Parte de la historiografía peruana ha atribuido la ausencia de un nacionalismo a la existencia de una clase dirigente fragmentada, que fue incapaz de articular un proyecto cohesionador (Bonilla, 1974; Cotler, 1986; Gotenberg, 1989). Otros se han enfocado en el nacionalismo de los actores sociales y la construcción identitaria al margen del Estado (Mallon, 2003; Manrique, 1981; Larson, 2002). No obstante, esta literatura también nos devela una incongruencia o falta de sintonía discursiva dentro de los actores sociales y políticos. Esta fractura entre los sectores populares e indígenas con su clase política constituirían el nudo gordiano del Perú, y el que Jorge Basadre nítidamente reconoció en las primeras décadas del siglo veinte, al señalar que el "problema y posibilidad [del Perú se originan y resuelven en estas dos variables], "organizar el Estado sobre la Nación [...] Ya no la Nación humillada y olvidada por el Estado" (Basadre, 1931:223).

A diferencia de lo sucedido en Chile, en el Perú fue difícil construir y mantener un discurso unívoco a lo largo de la guerra. El desplome del gobierno de Prado y las facciones civilistas del poder, producto de la arremetida de Piérola al gobierno y la posterior derrota en las puertas de Lima, abrieron paso al período de ocupación. Estos eventos dieron paso a la descomposición política de la clase dirigente peruana, la que no logró consensuar un discurso respecto de cómo debían enfrentarse las condiciones adversas por las que atravesaba la nación.

El discurso bélico nacionalista de carácter civilizador ya era esgrimido por la prensa al momento de la ocupación chilena de Antofagasta. En la Paz, El Comercio trataba de "filibusteros" a los chilenos por las acciones cometidas en sus costas, condenando el hecho por considerarlo un escándalo "inaudito a su propia nación, a la inocencia de América y al mundo civilizado", reflexión que más adelante lo hace aseverar que el "gobierno chileno ha retrocedido a los tiempos bárbaros de la historia". La idea de pueblo bárbaro fue vinculada a la imagen guerrera como parte de la arenga que invocaba el exterminio de todo lo ajeno a la civilización "Mueran los cobardes araucanos, porque su puñal ha rasgado nuestra hermosa tricolor, porque salvajes, han consumado el crimen más infame el suelo bendito de la patria" (El Comercio, La Paz, 28 de febrero de 1879,1$)$.

$\mathrm{Al}$ establecer la ocupación como un acto producto de la barbarie, que establecía la legitimidad del conflicto, ya que los pueblos civilizados debían actuar al unísono para defender a las naciones portadoras de la civilización, el discurso civilizatorio tiene como objeto comprometer la ayuda de los pueblos que se declaraban ajenos y enemigos de la barbarie. 
Con la declaración de la guerra, a principios de abril, la opinión pública peruana no se hizo esperar y comenzó a plantear sus descargos. La intromisión de Perú en el conflicto bajo una concepción americanista condicionó el discurso bélico peruano al fijar la causa como un problema que involucraba a todas las naciones y pueblos civilizados (Arellano, 2014). El gobierno de Mariano Ignacio Prado, a mediados de abril, al enterarse de la destrucción de algunos establecimientos en Iquique y Mollendo, considerándolos "incalificables" y contrarios a "las leyes del honor y la justicia, actos de barbarie", que merecen ser respondidos: "nuestra victoria será tan esplendida cuán grande la reprobación de toda la América a la conducta vandálica de Chile" (El Peruano, Lima, 18 de abril de 1879, 337). El periódico oficialista El Peruano se ordenó con esta mirada, por eso denuncia al gobierno chileno como ejecutor de una guerra propia de los "pueblos bárbaros". El bombardeo en el litoral peruano de Iquique y Mollendo fue utilizado para cuestionar la calidad de nación civilizada que ostentaba Chile, acusando la destrucción de "lugares indefensos" como ferrocarriles y muelles: “¡Cómo! ¿Nada significan los progresos de la ciencia?, ¿nada valen los límites puestos por el derecho y los excesos de la lucha? ¿Nada importan los progresos de la civilización cristina? ¿Qué campaña es esta, que se inicia con actos de salvajismo en el siglo XIX?". Para este redactor, las acciones bélicas chilenas se asimilan a las "hordas del Amazonas", acto que calificó como una infamia a la América que escandaliza al mundo entero (El Peruano, Lima, 17 de abril de 1879, 335). Lo bárbaro en el contexto de guerra es entendido como la destrucción y el pillaje que fue asimilado al salvajismo ajeno a las leyes, y en este caso de las guerras de las naciones civilizadas.

En el discurso bélico peruano, la barbarie es representada por la figura del "araucano" y el "roto chileno" y de hecho en las primeras publicaciones del satírico El Murciélago, redactado por Manuel Atanasio Fuentes, que salió a la luz en abril luego de declarada la guerra, escribió una canción titulada "La Araucana", que representaba la imagen despiadada del pueblo chileno: "Yo quiero mil peruanos /Colgados de un penol, /Racimo que algún día /Regale a mi nación" (El Murciélago, Lima, 26 de abril de 1879, 16). El roto, personaje que representa a los sectores populares que engrosaron las filas del ejército chileno, fue también utilizado como artificio discursivo para establecer la imagen de pueblo ajeno de las bondades de la civilización (Klaiber, 1978; Arellano, 2013). Se acusa en este sentido que las tropas chilenas practican el saqueo, el que es considerado como un principio incongruente con las naciones civilizadas, irónicamente se declara: "Robar, robar que así lo hacen/Los pueblos civilizados; /Robar, que si no, no tienen /Con qué comer los soldados /Robar, robar y robemos /Que, en buena geografía /El que no roba no es hombre /Digno de rotería" ( $E l$ Murciélago, Lima, 7 de junio de 1879, 61). Meses más adelante El Murciélago realizó una mirada retrospectiva, pero de Chile, argumentando cómo históricamente este pueblo se caracterizaba por el saqueo, y con sarcasmo encabezó su columna "Civilización chilena". Su argumento tenía como objetivo explicar el "antiguo prurito de robar" de este pueblo (El Murciélago, Lima, 17 de junio de 1879, 181). Los publicistas peruanos condicionados por el discurso americanista debieron ajustar sus arengas bélicas al definir el carácter bárbaro del pueblo chileno como argumento legítimo para justificar la intervención en la guerra.

Igual que los publicistas y políticos chilenos, para los peruanos este conflicto adquiría un significado superior a una simple diferencia diplomática o de índole económica. Lo que estaba en juego para estos arquitectos de la retórica era un conflicto de proporciones que superaba claramente la simple afrenta entre dos pueblos, ya que su resultado podía definir el destino del mundo civilizado. Por lo menos así lo estableció La Sociedad, organismo oficial del arzobispado peruano, al afirmar que la guerra tiene a todo el "mundo civilizado en suspenso" esperando el desenlace de esta guerra que "ocupará muy importantes páginas de la historia". Enterados de lo sucedido en Pisagua, este periódico acusa que no se han respetado "los principios universales de la civilización y la humanidad, semejando a los pueblo bárbaros de la Edad Media". Siguiendo las palabras y el sentido de este periódico tras la invasión de Pisagua, se abrían cometido "crímenes y atrocidades" como fusilamiento de heridos y atropellos de mujeres, todos hechos repudiables (La Sociedad, Lima, 7 de noviembre de 1879, 1).

El sentido bárbaro que se buscaba otorgar a las acciones bélicas chilenas procuraba presentar a las fuerzas aliadas peruano-bolivianas como a las verdaderas representantes de los pueblos civilizados, antepuestas al salvajismo chileno, ordenando su retórica a la búsqueda del apoyo internacional. Los 
arengadores peruanos en esta primera instancia de la guerra apuntaron principalmente su discurso para asimilar al Perú como representante de las naciones civilizadas. La retórica nacionalista peruana, pieza clave en la construcción de una identidad cohesionadora, fue relegada por una retórica civilizadora que apuntaba más bien a conseguir el favor externo que la cohesión interna. El discurso peruano en este sentido se desgastó principalmente en alcanzar la cohesión internacional, al estar condicionada su participación en la guerra a la alianza con la nación boliviana sobre la base de un discurso americanista que tenía como fin conseguir el favor de los pueblos civilizados.

Si bien es cierto la opinión pública peruana fue afectada en su independencia al ser arrestados los directores de los periódicos, al no respetar la ley que los obligaba a poner el nombre de los autores de los artículos y editoriales durante el gobierno de Piérola (Gargurevich, 1991: 98). La concepción civilizadora continuaba siendo utilizada en las obras narrativas de carácter bélico. Por ejemplo, El Peruano, voz oficial del gobierno, en los primeros días de enero publica un editorial en respuesta a lo que sucedió en Moquegua: "el modo irregular y contradictorio a las prácticas de las naciones civilizadas como Chile hace por tierra y por mar la guerra a las repúblicas aliadas", argumentación en la que advierte a las naciones neutrales y amigas que tomaran nota del hecho y que tengan claro del lado en que está la justicia, ya que con esto se resucita a la "barbarie" que había sido conquistada "hace tres siglos a la causa del progreso y de la civilización" (El Peruano, Lima, 9 de enero de 1880, 1).

El relato bélico si bien en su contenido y orientación no sufrió grandes transformaciones con la administración política de Piérola, puede destacar algunos matices en el diseño de las construcciones retóricas. La comparación entre las trayectorias históricas de ambos pueblos se convirtió en una nueva forma para aplicar la matriz ideológica civilizadora, pero esta estuvo dirigida fundamentalmente a desestimar los argumentos elevados por los artífices del discurso en Chile. Esto obligó a la opinión pública en el Perú a realizar una revisión de su historia y cernir una nueva mirada hacia el pasado. Es el caso de Jorge Polar en Arequipa, que en el periódico de El Eco del Misti, afín a Piérola, interpretó la historia chilena sobre la base de un personaje histórico considerado representativo de la nación, que en este caso puntual fue el mítico ministro Diego Portales. Polar, planteó la tesis en virtud de que la historia de los pueblos se pueden interpretar por sus grandes hombres, argüía que si bien la historia de Chile no arroga grandes hombres, sostiene que sí tiene hijos dignos de él como Portales, cuya principal virtud "es pura y simplemente saber azotar, y saber matar". Chile no necesitaba más instituciones que "un sólido patíbulo, rodeado de bastantes gendarmes, y un buen azotador que no se canse jamás" (El Eco del Misti, Arequipa, 16 de febrero de 1880, 2).

La historia entre ambos pueblos se destaca por su antagonismo, señalándose que "lo único que puede haber es antítesis, contrastes", acerca de la idea de un pueblo sumido en el oscurantismo, frente a una nación iluminada bajo las virtudes de la civilización. La identidad se gesta entonces como un momento de alteridad (El Eco del Misti, Arequipa, 16 de febrero de 1880, 2).

Otra estrategia discursiva por parte de los arengadores peruanos, para establecer el sentido de la guerra respecto del binomio de la civilización y la barbarie, se refiere a las denuncias de las prácticas bélicas ejecutadas por el ejército en las diferentes campañas militares. Es el caso de la ocupación de Tarapacá, que fue definida por El Peruano como de carácter bárbaro. El redactor del editorial, José Casimiro Ulloa, cuestionó los medios utilizados por los chilenos al apropiarse de bienes particulares, poniendo especial énfasis en las salitreras, adueñándose como "conquistadores", dice Ulloa, de todas las propiedades de la provincia ocupada por las armas. Este hecho es definido sobre la base del mismo lenguaje político civilizador, al acusar a Chile de renovar "las prácticas de la guerra de las edades bárbaras". Calificó en duros términos a Chile, por "obligar" a los productores salitreros a trabajar en beneficio de Chile y con ironía señaló: "Esta es la República, no obstante, que se jacta de estar más adelantada en civilización en su Sudamérica". Su objetivo fue desechar el argumento chileno regenerador, denunciando que las fuerzas chilenas solo han llevado "el saqueo y la exterminación donde pone sus plantas", como muestra clara de la barbarie de ese pueblo (El Peruano, Lima, 25 de febrero de 1880, 88).

En la misma línea argumental, Jorge Polar en Arequipa publicó un artículo titulado "La última infamia", en donde la barbarie -a juicio de estos publicistas- se evidencia en las prácticas de la guerra. Polar denuncia el salvajismo cometido por 
los chilenos en los pueblos de Mollendo, Mejía y Pisagua. Sus palabras manifiestan la indignación por "esos pueblos incendiados, esas casas saqueadas han quedado allí dando testimonio de la presencia de los bárbaros". La destrucción y el saqueo son la imagen que los periodistas peruanos tratan de imprimir, como una forma de despertar la indignación del pueblo para poder alcanzar la anhelada cohesión social y política para enfrentar la guerra. El sentido es claro: el enemigo ("los hijos del pueblo maldito") solo deja huellas de destrucción a su paso. Esa es la imagen explotada por este publicista para motivar el desprecio y crear el sentido de la lucha. La guerra realizada por Chile es asimilada a "la guerra de Alarico y Atila", lo que lo llevó a concluir que "esta [es] la guerra de la barbarie contra la civilización, del derecho contra el pillaje" (El Eco del Misti, Arequipa, 15 de marzo de 1880, 1).

Las derrotas de los aliados y el avance del Ejército chileno se convierten en un hecho para explicar cuál es el sentido de la guerra, y detener el avance de la barbarie. El origen de la guerra es ahora encapsulada como una forma de venganza frente a los atropellos y la destrucción que son definidos dentro del espectro de lo bárbaro.

Toda la opinión pública consensuó esta estrategia discursiva para promocionar la cohesión nacional. No está de más señalar que la religión se hace partícipe de este argumento civilizador. Por ejemplo, La Sociedad, voz oficial de la Iglesia católica peruana, publicó un artículo que fue rubricado por Carlos A. García, en el que se sostuvo que Chile "todo lo ha violado", haciendo directa referencia a la declaración de guerra y la campaña militar chilena, "resucitando -arguye García- de este modo, en las guerras, dulcificadas ya por la religión católica, toda la barbarie y toda la crueldad, de las antiguas de que nos había horrorizada la historia" (La Sociedad, Lima, 16 de marzo de 1880, 1). Los hechos cometidos en el desarrollo de la guerra se convierten -parafraseando a Carmen McEvoy (2010) - en "armas de persuasión" para provocar en primera instancia la indignación y repudio a lo definido como bárbaro y, luego, la unificación para enfrentar tal amenaza.

Con este mismo objetivo, en la construcción de la imagen salvaje de Chile El Peruano escribió en sus columnas que con virulencia "Los araucanos del Pacífico [...] han comenzado a repetir en nuestros mares del Norte, las escenas de Barbarie que con escándalo de la civilización, realizan desde hace un año en nuestras aguas del sur". Los bombardeos de la escuadra chilena en el litoral ariqueño despertaron la indignación, calificando el hecho como salvaje al denunciar la destrucción de puertos, guaneras y propiedades particulares. Carlos Polar exaltaba en Arequipa: "Nunca creímos encontrar hidalguía en los hijos degenerados de Pedro de Valdivia, pero nunca también supusimos que hicieran lujo de ruindad y gala de perfidia”. Las palabras de este publicista buscan subrayar la brutalidad chilena e imponer un discurso transversal de la opinión pública peruana.

El discurso pierolista de corte civilizador marca claramente una coherencia en términos argumentales con lo que se había sostenido con antelación dentro de la opinión pública peruana. Dichos argumentos alimentaron todo tipo de arengas como la efectuada por José Cortés, el prefecto y comandante general del departamento de Huanuco, ubicado en la parte nor-central de Perú, quien dirigiéndose a sus habitantes acusa a Chile de pueblo "traidor", denunciando que los departamentos del sur se han "devastado y cubierto de cadáveres" en el marco de lo que él llama "furores de salvajismo". "No está lejos el castigo y la reparación", sentenciando la necesidad de la purificación del "suelo sagrado de los Incas" y cerrando su arenga al recalcar la calidad bestial del ejército: "Las hordas chilenas tiemblan ante la justicia de nuestra causa" (El Peruano, Lima, 8 de julio de 1880, 14).

Pero la pesadumbre no le resta fuerza al mensaje guerrero, que niega a Chile toda misión regeneradora. En una arenga callejera, José Ángel Medina Abelardo en Lima señaló: "los bárbaros del Sur no tienen ningún hecho providencial que realizar, ni menos traen en su venas la sangre fecunda de una regeneración", el Perú para este orador "está llamado en la América a un destino superior". Los hechos de sangre y dolor que sufrieron ambos pueblos fueron refrendados por discursos que difundieron y perpetuaron la imagen de otro, construidas sobre el antagonismo entre civilización y barbarie. Al cierre de su discurso, Medina Abelardo estampó el retrato que los ciudadanos de Lima, ante la inminente invasión se hicieron de no solo del ejército chileno, sino de una nación entera:

Los bárbaros se acercan a la gran ciudad: traen la tea, el puñal; sus corceles, salvajes como sus jinetes, en violentos torbellinos de polvo, viene talando los campos y destruyendo los caminos: el horizonte se oscurece con 
siniestras tinieblas: es el humo del incendio que se arremolina y combate en los aires de la polvareda que levantan los incendiarios: el fuego en largas lenguas de infernal monstruosidad, parece llamar con sus chisporroteo a la venganza tremenda. Levántate Lima, sube a tus azoteas, escala tus colinas y contempla el terrible panorama en tu campiña. Pueblo que sabías deleitarte en los placeres, álzate grandioso a la hora de la venganza, empuña tu arma, busca tu puesto; salva tu hogar y tu honor o muere valiente, por la patria. No se diga que Lima cayó como Babilonia entre las carcajadas de un festín o como Roma en la disolución de un pueblo No! (El Nacional, Lima, 19 de noviembre 1880).

Son más que elocuentes las palabras usadas por este orador peruano en su proclama. El discurso civilizador peruano se derrumbó a la par con la caída de Lima, producto de la derrota de Chorrillos y Miraflores, estableciéndose la ocupación de la ciudad y suprimiéndose los periódicos existentes en la ciudad. La guerra entraba en una nueva etapa que exigía que los arengadores readecuaran sus estrategias discursivas. La ocupación chilena será una nueva etapa para la guerra y las arengas.

\section{Conclusiones}

El discurso civilizador en el Perú adquiere un matiz de universalidad en la medida que busca equiparar la condición de Perú con las naciones civilizadas, pero a partir de la exacerbación de los actos de salvajismo cometidos por Chile en la guerra. Los publicistas peruanos, como hemos señalado, pusieron menos énfasis en la construcción de una identidad, al no observarse en sus arengas ejercicios introspectivos o que promuevan el nacimiento de una idea de nación, a diferencia de lo practicado en Chile.

El discurso civilizador tuvo en este sentido aplicaciones y resultados distintos en las retóricas bélicas de ambas naciones. La dirección de los discursos peruanos siempre han tendido más a definir una identidad a partir de la negación, es decir, de lo que no son, situación condicionada en primera instancia por el discurso americanista, el que le sirvió al Perú para legitimar su inserción en la guerra, pero a la luz de los hechos fue incapaz de reaccionar con un discurso más nacionalista que contribuyera a generar la tan anhelada cohesión para enfrentar al enemigo.

A diferencia del discurso nacionalista chileno que se tejió de adentro hacia fuera, en el sentido de que la concepción civilizadora sirvió para cristalizar una historia y una identidad que lograra generar la cohesión social y política, y solo después se cruzaron los puentes para insertarse con el "mundo civilizado", en el Perú, el discurso civilizador siempre invocó ser partícipe de las sociedades civilizadas, olvidándose de crear una identidad, lo que significó que la idea de nación peruana se terminase diluyendo dentro de las naciones civilizadas. Condicionado por esta retórica, se debió recurrir a la mecánica de definir y exacerbar las condiciones bárbaras de un "otro", en este caso el enemigo, definiendo de forma antagónica su identidad.

El nacionalismo extrovertido -en las palabras de Véliz- fue mucho más sólido en el Perú que en Chile, debido a que este último fue capaz de construir un relato más híbrido que le permitió exacerbar elementos particularistas de índole nacional, pero insertos en el concierto de las naciones civilizadas. El problema entonces no es el fondo del discurso, ya que tanto en Chile como en el Perú arengaron el discurso civilizador como legitimador de la guerra, la diferencia está en las estrategias discursivas para aplicar esta concepción.

\section{Agradecimientos}

Este artículo se inscribe en el proyecto FONDECYT No 1140564 de la Comisión Nacional de Investigación Científica y Tecnológica (CONICYT).

\section{Referencias}

Arellano, J. C.

2012 Discursos racistas en Chile y Perú durante la Guerra del Pacífico (1879-1884). Estudos Ibero-Americanos, 38(2), 239-264.

Arellano, J. C.

2014 La Guerra del Pacífico y el americanismo republicano en el discurso bélico peruano. História Unisinos, 18(2), 392-402.
Basadre, J.

1931 Perú: Problema y posibilidad. Ensayo de una síntesis de la evolución histórica del Perú. Lima: Librería Francesa Científica y Casa Editorial E. Rosay.

Bonilla, $\mathrm{H}$.

1980 Un siglo a la deriva, ensayos sobre el Perú y Bolivia y la guerra. Lima: Instituto de Estudios Peruanos. 
Burns, E. B.

1990 La pobreza del progreso América Latina en el siglo XIX. México: Siglo Veintiuno Editores.

Cid, G.

2009 "Un ícono funcional: la invención del roto como símbolo", En Nación y nacionalismo en Chile. Siglo XIX, ed. Gabriel Cid y Alejandro San Francisco. Santiago: Centro de Estudios Bicentenario.

Cotler, J.

1986 Clases, Estado y Nación en el Perú. Lima: Instituto de Estudios Peruanos.

Crawford, N.

2006 How Previus Ideas Affect Later Ideas. In The Oxford Handbook of Contextual Political Analysis, de Robert Goodin and Charles Tilly, 266-286. New York: Oxford University Press, 2006.

Figueroa, P. P.

1901 Diccionario biográfico de Chile (4th ed., Vol. 3). Santiago: Imprenta y Encuadernación Barcelona.

Gargurevich, J.

1991 Historia de la prensa peruana (1594-1990). Lima: La Voz Ediciones.

Gootenberg, P.

1989 Between Silver and Guano: Commercial Policy and the State in Postindependence Peru. New Yersey: Princeton University.

Habermas, J.

1994 Historia y crítica de la opinión pública. México: Mass Media.

Howard, M., \& Roger Louis, W. M.

2002 The Oxford History of the Twentieth Century. Great Britain: Oxford University Press.

Jocelyn-Holt, A.

1998 El peso de la noche: nuestra frágil fortaleza histórica. Santiago: Planeta, Ariel.

Klaiber, J.

1978 Los "cholos" y los "rotos": actitudes raciales durante la Guerra del Pacífico. Histórica, 2, 27-37.
Larson, B.

2002 Indígenas, elites y Estado y la formación de las repúblicas andinas. Lima: Pontificia Universidad Católica del Perú, Instituto de Estudios Peruanos.

Mallon, F.

2003 Campesino y nación. La construcción de México y Perú poscoloniales. México: CIESAS, El Colegio de San Luis, El Colegio de Michoacán.

Manrique, N.

1981 Campesinado y nación: las guerrillas indígenas en la guerra con Chile. Lima: Centro de Investigación y Capacitación, Editora Ital.

McEvoy, C.

2007 ¿República nacional o república continental? El discurso republicano durante la Guerra del Pacífico, 1879-1884. In C. McEvoy \& A. M. Stuven (Eds.), La república peregrina. Hombres de armas y letras en América del sur, 1800-1884 (pp. 531-562). Perú: Instituto de Estudios Peruanos, Instituto Francés de Estudios Andinos.

McEvoy, C.

2010 Armas de Persuasión Masiva. Retórica y Ritual en la Guerra del Pacífico. Centro de Estudios Bicentenario.

McEvoy, C.

2011 Guerreros civilizadores. Política, sociedad y cultura en Chile durante la Guerra del Pacífico. Santiago: Ediciones Universidad Diego Portales.

Sánchez Arteaga, J. M.

2007 La racionalidad delirante: el racismo científico en la segunda mitad del siglo XIX. Revista de Asoc. Esp. Neuropsiq., XXVII, 383-398.

Starobinski, J.

1999 La palabra civilización. Prismas. Revistas de Historia Intelectual, 9-36.

Véliz, C.

1984 La tradición centralista de América Latina. Barcelona: Ariel.

Viroli, M.

1997 Por amor a la Patria, un ensayo sobre el patriotismo y el nacionalismo. Madrid: Acento Editorial.

\section{Notas}

Por discursos bélicos entendemos todas aquellas alocuciones $\mathrm{y}$ escritos dirigidos por individuos y organizaciones al espacio público que reflexionan acerca de lo político y en particular respecto de la guerra. Esto amplía el campo de búsqueda, ya que los artículos en los periódicos de la época, obras o tratados teóricos son considerados parte importante de la investigación, pues buscan influir el debate público otorgándole un sentido trascendente al conflicto. Estos discursos claramente son portadores de ideas que tienen como objetivo incidir en la acción, y que pueden ser utilizados tanto para la anulación de intereses de un grupo en particular como para la justificación de los intereses o también dirigirse a la compresión o reconocimiento de nuevos intereses (Crawford, 2006: 266-283).

2 Según Jürgen Habermas (1994), esto es producto de un fenómeno histórico que se presenta al emerger el Estado Moderno, en donde se origina un desprendimiento de la sociedad civil, asumiendo esta última un rol independiente y crítico de la autoridad estatal. 
